\title{
Microphthalmia with linear skin defects syndrome
}

INSERM

\section{Source}

INSERM. (1999). Orphanet: an online rare disease and orphan drug data base. Microphthalmia with linear skin defects syndrome. ORPHA:2556

MIDAS syndrome (Microphthalmia, Dermal Aplasia, and Sclerocornea), also called microphthalmia with linear skin defects syndrome, is characterized by ocular defects (microphthalmia, orbital cysts, corneal opacities) and linear skin dysplasia of the neck, head, and chin. It has been reported in less than 50 patients. Additional findings may include agenesis of corpus callosum, sclerocornea, chorioretinal abnormalities, hydrocephalus, seizures, intellectual deficit, and nail dystrophy. It is transmitted as an Xlinked dominant trait with male lethality. 